\title{
ANALYSIS OF AIR FLOW THROUGH THE ENGINE INTAKE AND EXHAUST DUCTS
}

\author{
Zbigniew Czyz $\dot{z}^{1 \otimes}$ \\ $1 \square$ Polish Air Force University, Faculty of Aviation, 35 Dywizjonu 303 Str., 08-521 Dęblin, Poland, \\ https://orcid.org/0000-0003-2281-1149, e-mail: z.czyz@law.mil.pl
}

Submitted: 2019-11-11 / Accepted: 2019-11-12 / Published: 2019-12-27

\begin{abstract}
The paper presents numerical analysis of charge exchange in an opposed-piston two-stroke engine. The research engine is a newly designed internal diesel engine. This unit is composed of three cylinders in which operate three pairs of opposed-pistons. The numerical investigations were carried out using ANSYS FLUENT solver. The geometrical model includes an intake manifold, a cylinder and an outlet manifold. The calculations specified a swirl coefficient obtained under steady conditions for fully open intake and exhaust ports as well as the CA value of $280^{\circ}$ for all cylinders. In addition, mass flow rates were identified separately in all of the intake and exhaust ports to achieve the best possible uniformity of flow in particular cylinders.
\end{abstract}

KEYWORDS: charge exchange, opposed-piston engine, CFD analysis, ANSYS fluent

\section{Introduction}

This article covers work on concept of the designed engine intake system. Its more detailed description is contained in articles [1] and [2]. Earlier solutions of the proposed construction included an inlet and outlet system with double-sided operation, i.e. both inlet and outlet channels were developed on both sides of the engine. It seems that this solution facilitates obtaining even medium supply and flow with the lowest losses. On the other hand, this solution requires the use of double collectors, which translates into increased weight. Meanwhile, it was decided to confront this solution with a solution based on one-sided supply and discharge of the refrigerant.

Today, the highly developed CFD calculation technique enables optimisation of such processes as: heat exchange [3] and charge exchange, forming a blend [4], combustion in the engine [5], and modelling of the injection process [6]. Paper [7] contains information regarding the aircraft engine operation conditions, whereas [8] describes the combustion in engine, which is also relevant to this article. Numerical analysis, in contrast to experimental research, enables validating design assumptions and avoid costly prototype preparation for experimental tests; consequently, the geometrical model can be optimised in countless variants not generating any production costs.

Numerous studies aimed to optimise the operation of internal combustion engines are conducted, e.g. the scavenging process in a two-stroke free piston linear engine has been modelled and simulated successfully based on the combination of a dynamic model and a CFD model, see [9]. The authors of [10] reviewed in detail conventional internal combustion engines and indicated twostroke ones as investigated most frequently for their advantageous construction and control. 


\section{Problem description and methods}

The main research problem aim of this paper is to design an intake and exhaust manifolds for the optimization of charge exchange in an opposed-piston two-stroke engine. The geometric model was made as the starting model for further analysis. Design assumptions were taken into account, in particular the unilateral way of delivering the load and unilateral discharge of exhaust gases (Fig. 1). Eight windows were made on both the intake and exhaust manifolds. The method of marking windows is presented in [1].

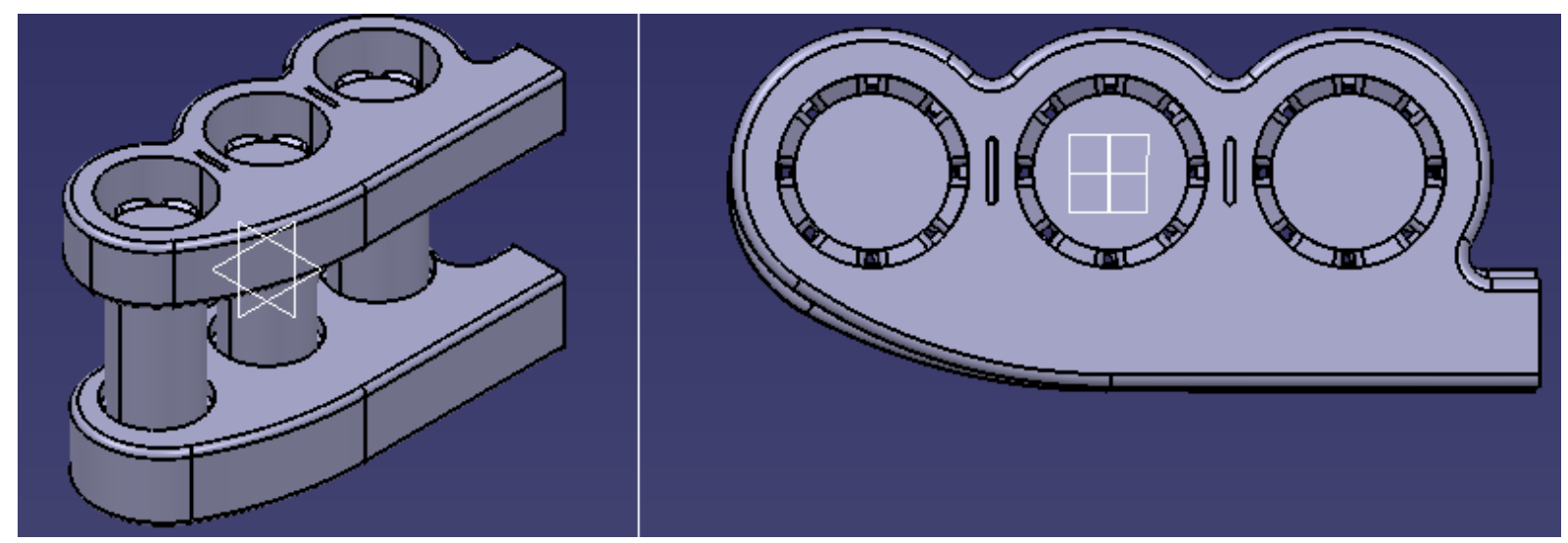

Fig. 1 View of the intake and exhaust manifold of the considered geometric model

The numerical investigations were carried out using ANSYS FLUENT solver. The geometrical model includes an intake manifold, a cylinder and an outlet manifold. A correctly prepared geometric model has enabled us to generate a mesh. In the central part of the cylinder, the mesh consists of hexa-cells, which enables us to simulate motion of pistons by growth of layers using the function of layering (fig. 2). Due to differences in geometric models and initial and boundary conditions, the number of cells in a mesh is minimised but a high quality mesh is maintained. Such an approach has eliminated the impact of mesh on results. The chamber covering the volume between the pistons is divided into two parts so a cut plane was created which was used to generate new layers or delete existing ones when the pistons move.

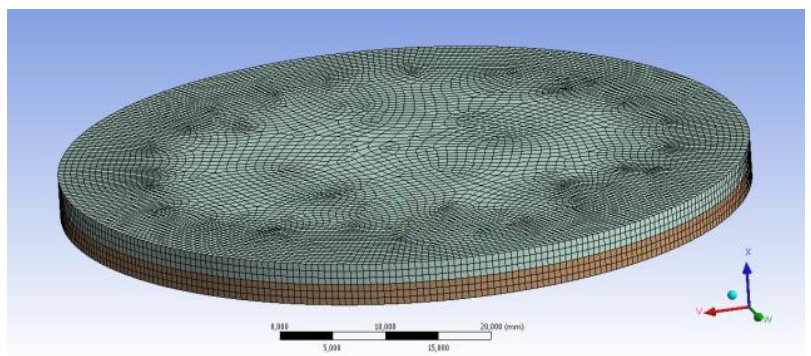

Fig. 2 View of the mesh of cylinder at the initial position of the pistons

\section{Results}

Fig. 3 shows the value of mass flow rate in individual inlet and outlet windows for cylinder No. 1 of the considered geometric model. 


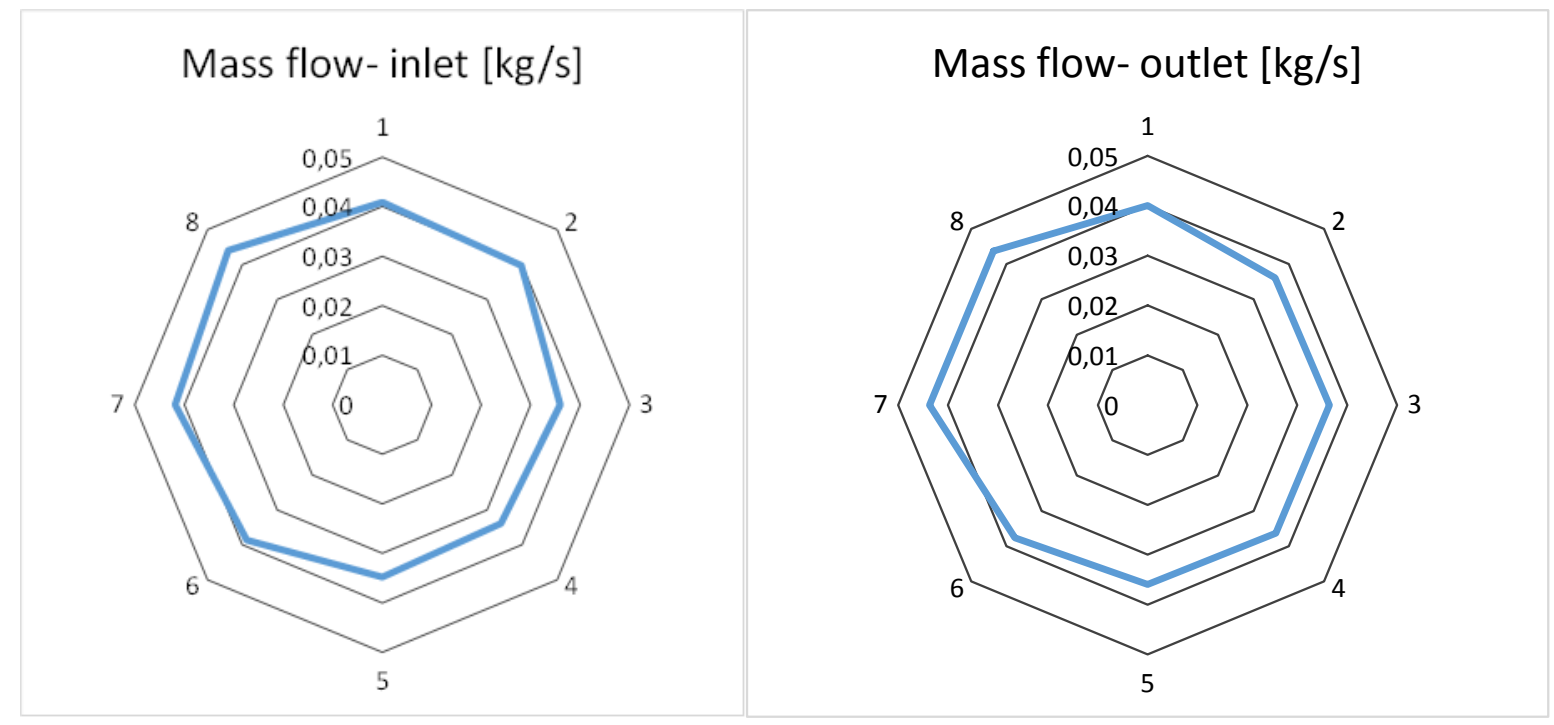

Fig. 3 Distribution of mass flow rate in individual inlet (left) and outlet (right) ducts for cylinder no. 1 of the considered geometric model

Figures 4 to 6 show graphically the results in the form of velocity and pressure contours on characteristic sections. The calculations for the model were carried out consistently for a pressure of $75 \mathrm{kPa}$.
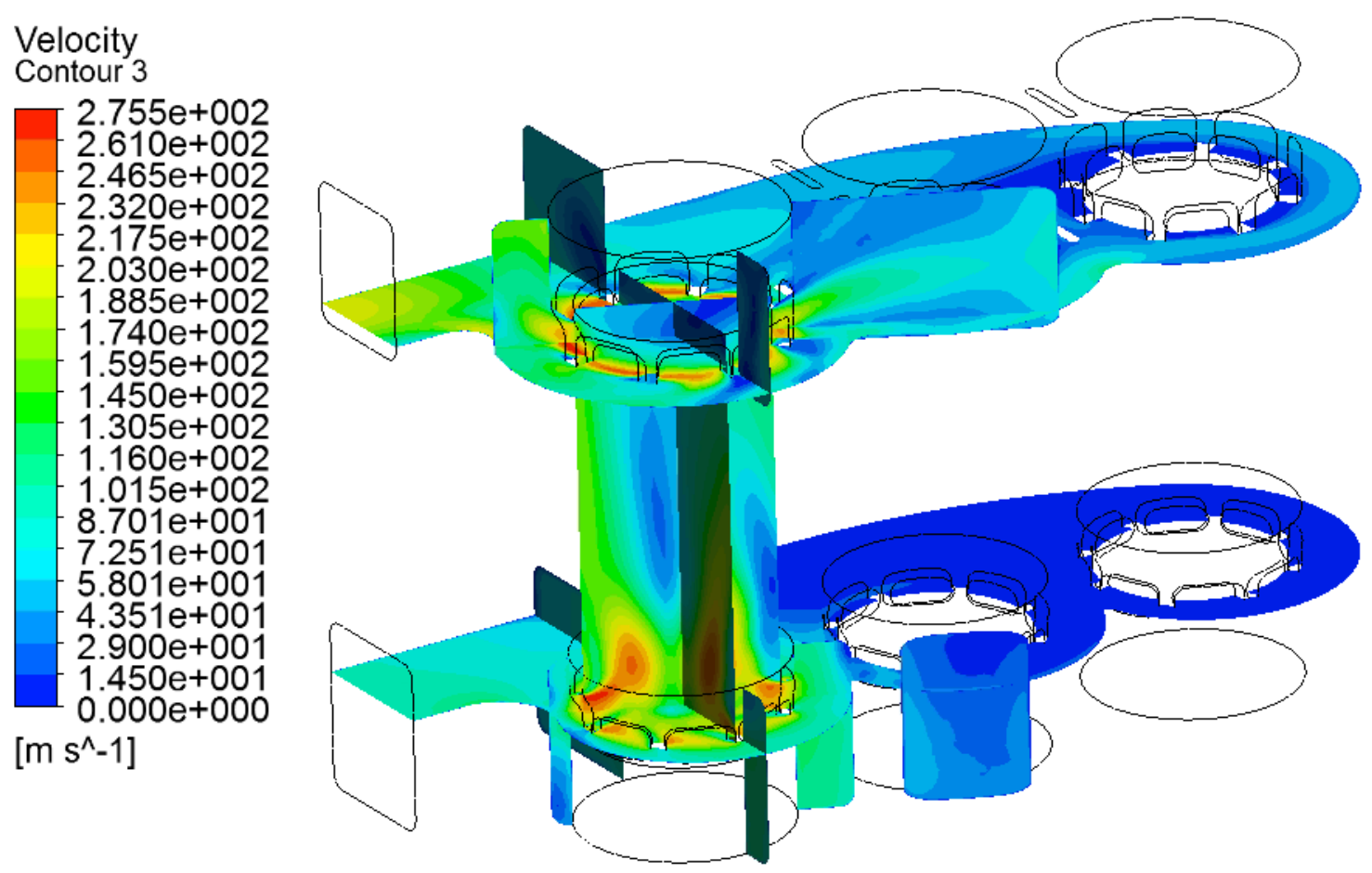

Fig. 4 View of selected sections of the analyzed geometry in terms of velocity field distribution 


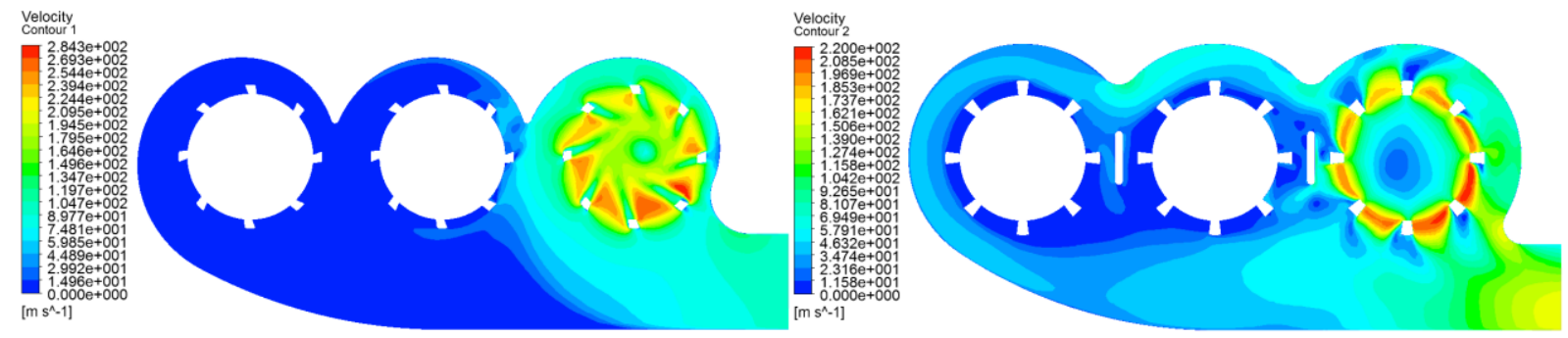

Fig. 5 Contour of velocity in the transverse plane passing through the inlet duct (on the left) and through the outlet duct (on the right) for cylinder no. 1 of the considered geometric model

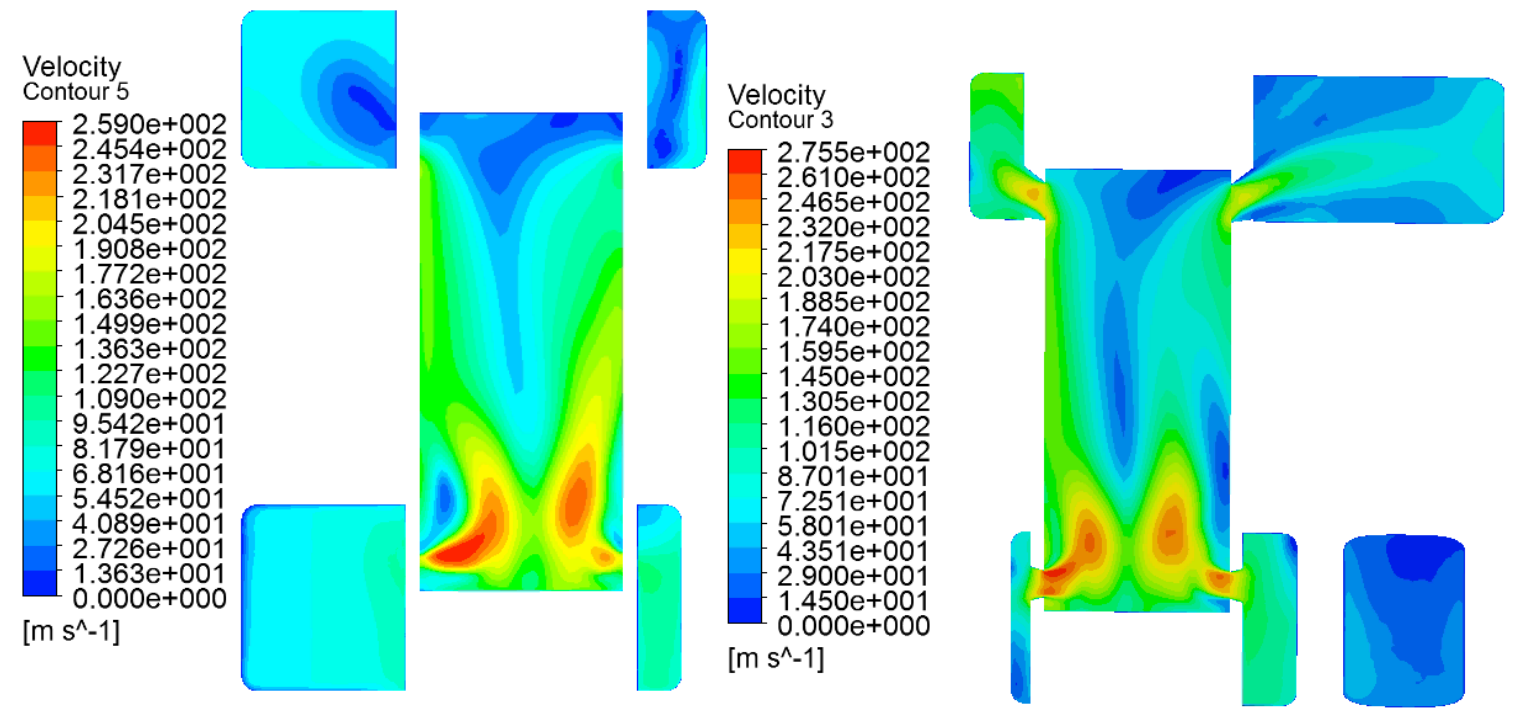

Fig. 6 Contour of the velocity in the longitudinal plane yz (on the left) and in the longitudinal plane rotated relative to the plane yz (on the right) for cylinder No. 1 of the considered geometric model

Fig. 7 shows the value of mass flow rate in individual inlet and outlet windows for cylinder no. 2 of the considered geometric model.

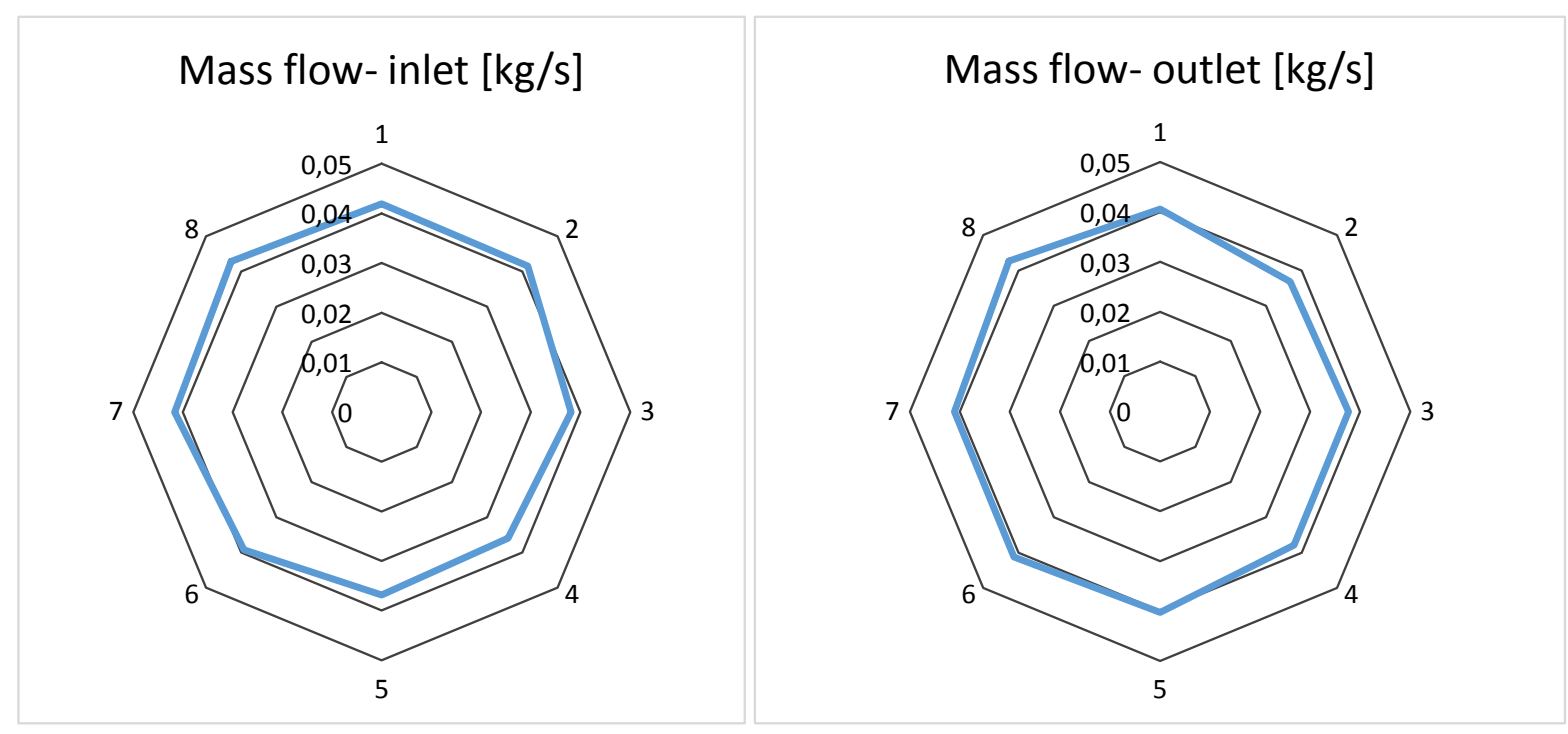

Fig. 7. Distribution of mass flow in individual inlet (left) and outlet (right) ducts for cylinder 2 of the geometric model under consideration 
Figures 8 to 10 show the results graphically in the form of velocity and pressure contours on characteristic sections.

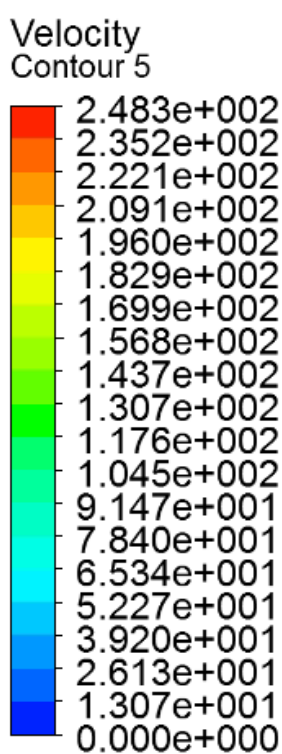

$\left[\mathrm{m} \mathrm{s} \mathrm{s}^{\wedge}-1\right]$

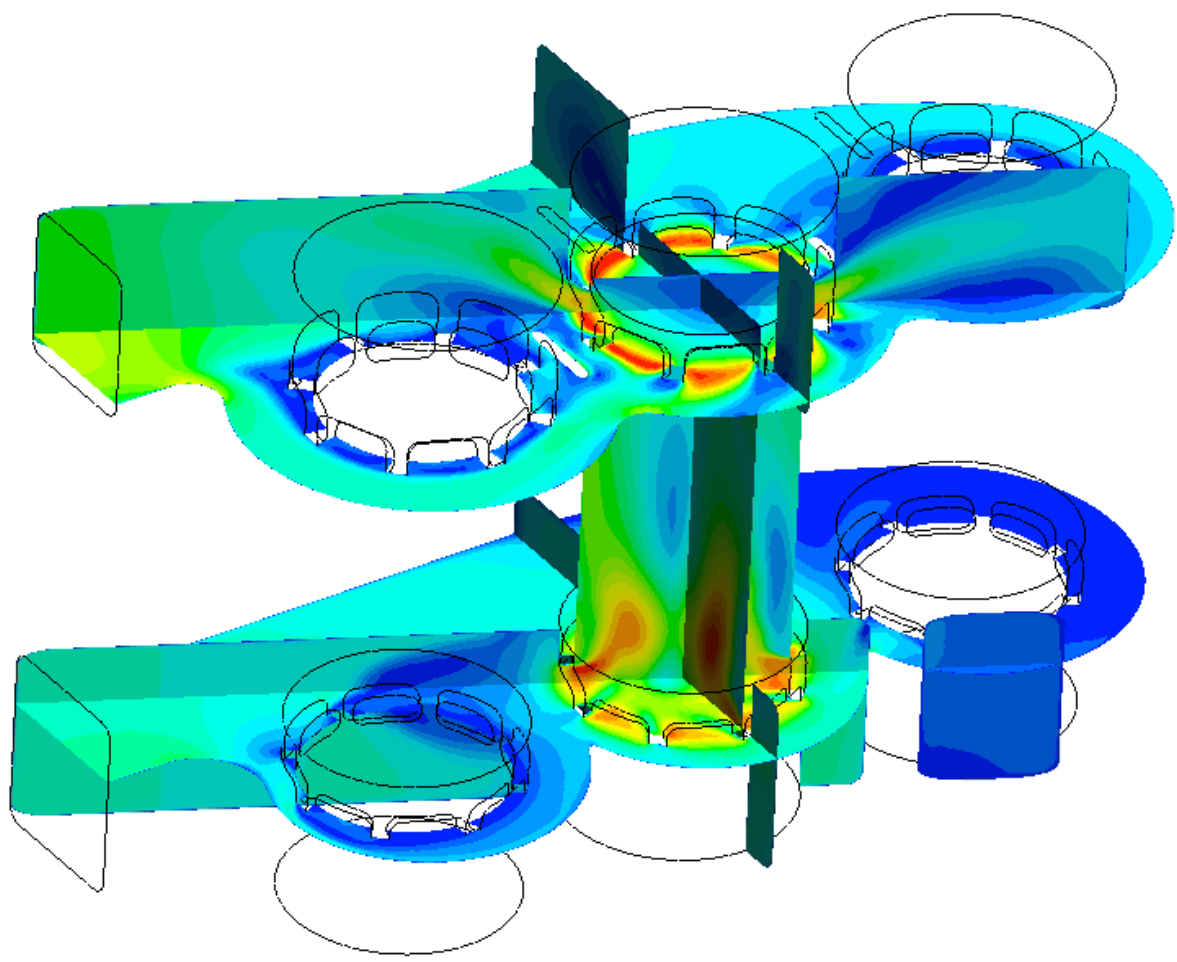

Fig. 8 View of selected sections of the analyzed geometry in terms of velocity field distribution
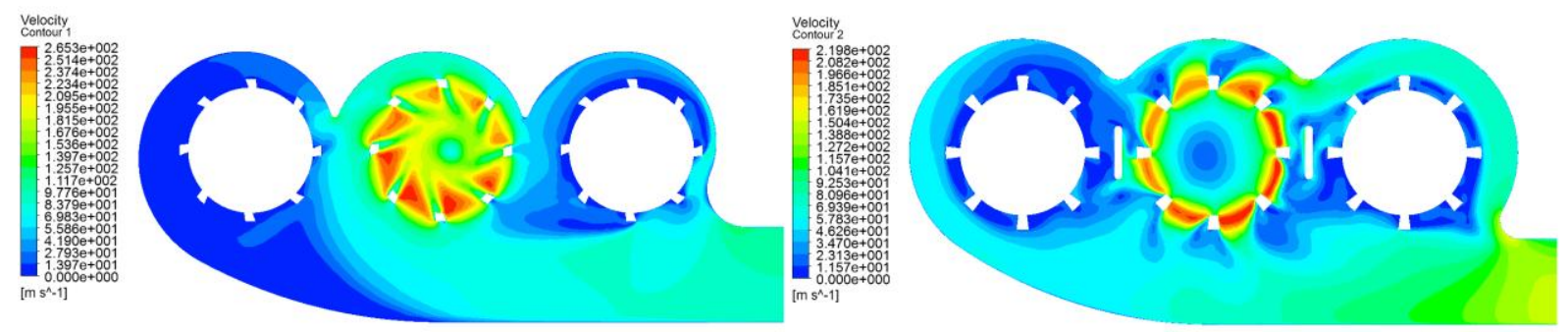

Fig. 9 Contour of speed in the transverse plane passing through the inlet duct (on the left) and through the outlet duct (on the right) for cylinder no. 2 of the considered geometric model

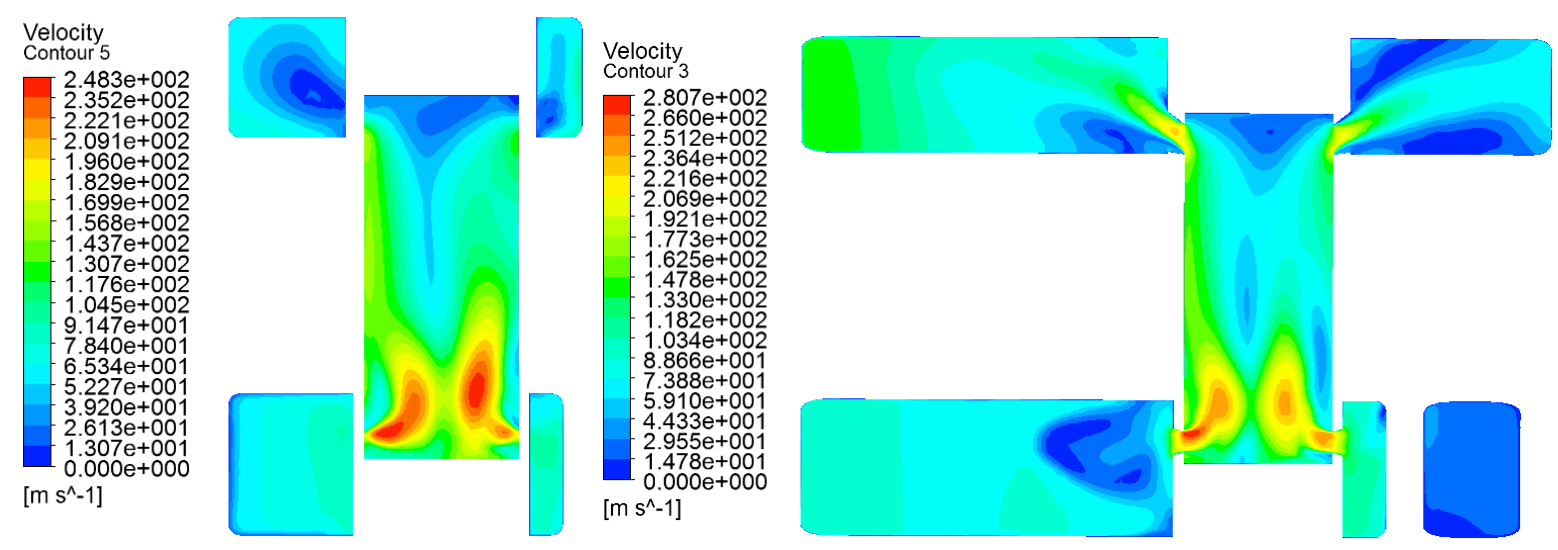

Fig. 10 Contour of the velocity in the longitudinal plane yz (on the left) and in the longitudinal plane rotated relative to the plane $\mathrm{yz}$ (on the right) for cylinder no. 2 of the considered geometric model 
Fig. 11 shows the value of mass flow rate in individual inlet and outlet windows for cylinder No. 3 of the considered geometric model.

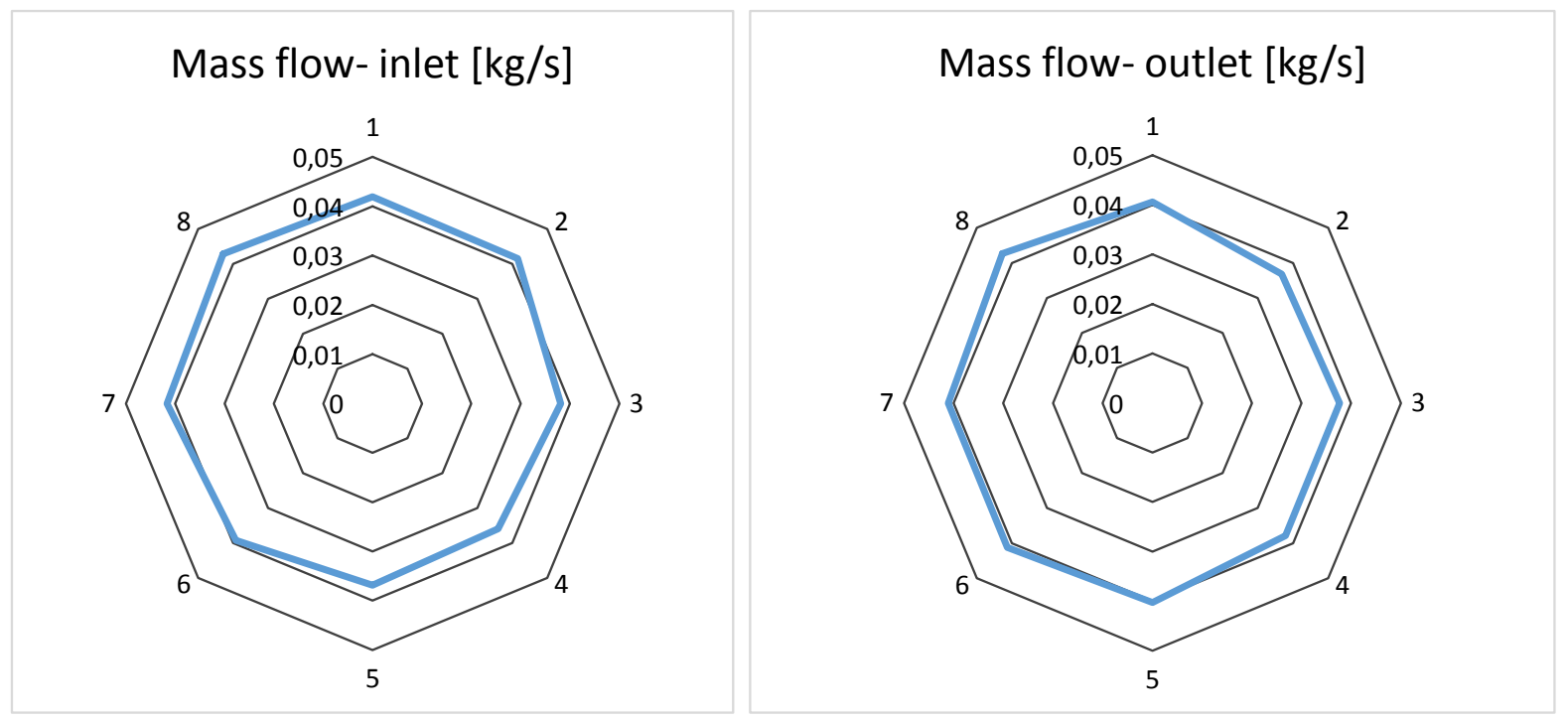

Fig. 11 Distribution of mass flow rate in individual inlet (left) and outlet (right) ducts for cylinder No. 3 of the considered geometric model

Figures 12 - 14 show the results graphically in the form of velocity and pressure contours on characteristic sections. The calculations for the model were carried out consistently for a pressure of $75 \mathrm{kPa}$.
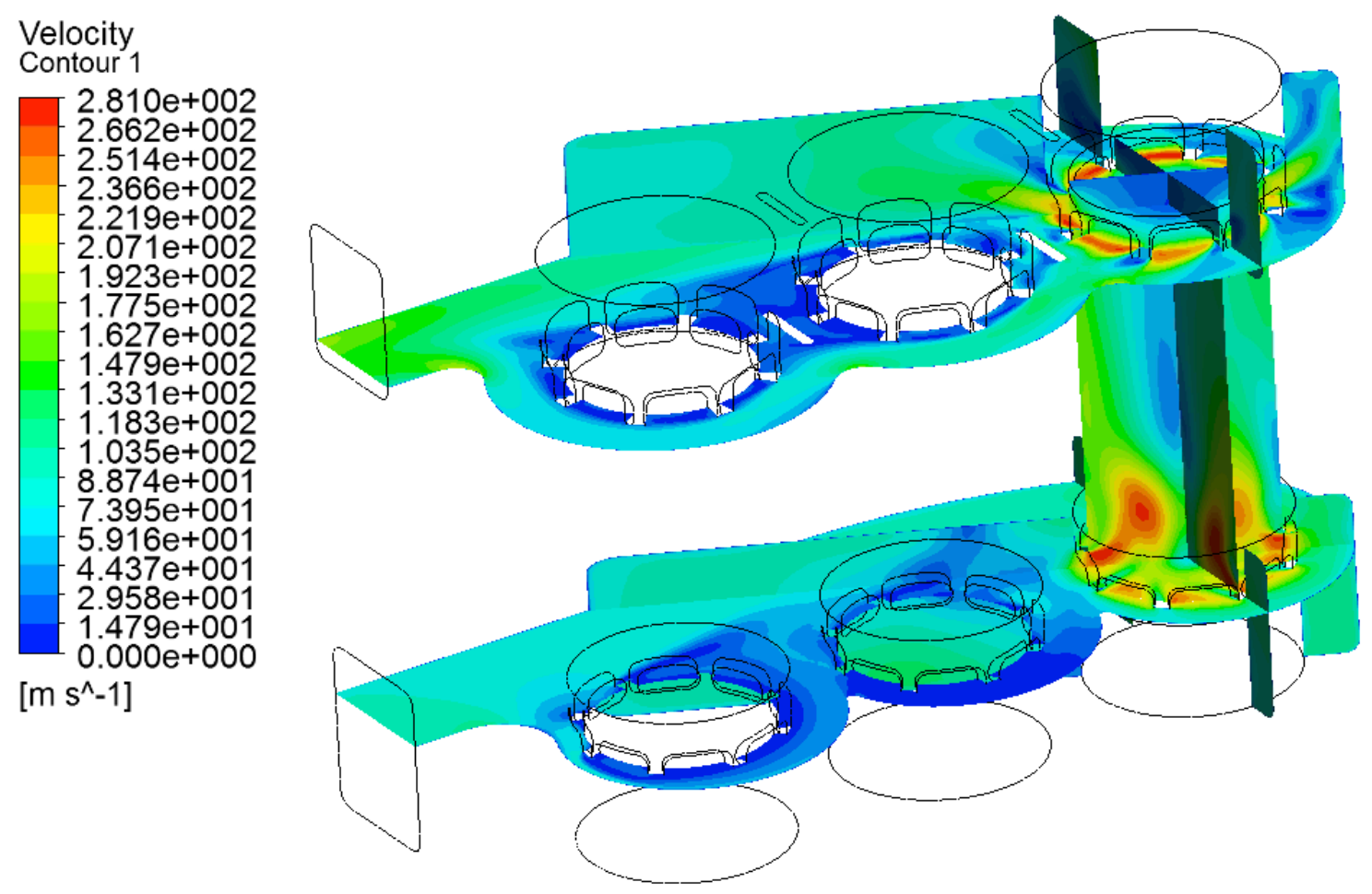

Fig. 12 View of selected sections of the analyzed geometry in terms of velocity field distribution 


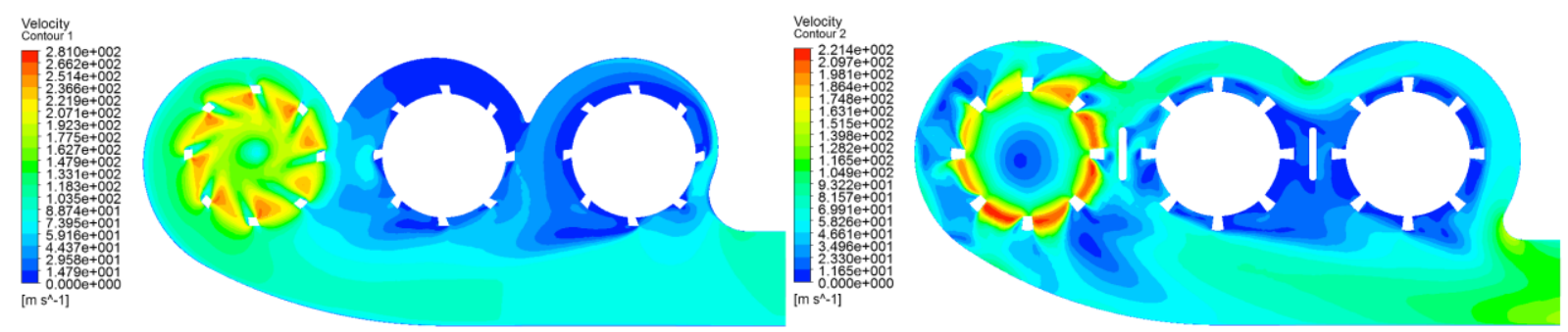

Fig. 13 Contour of velocity in the transverse plane passing through the inlet duct (on the left) and through the outlet duct (on the right) for cylinder no. 3 of the considered geometric model

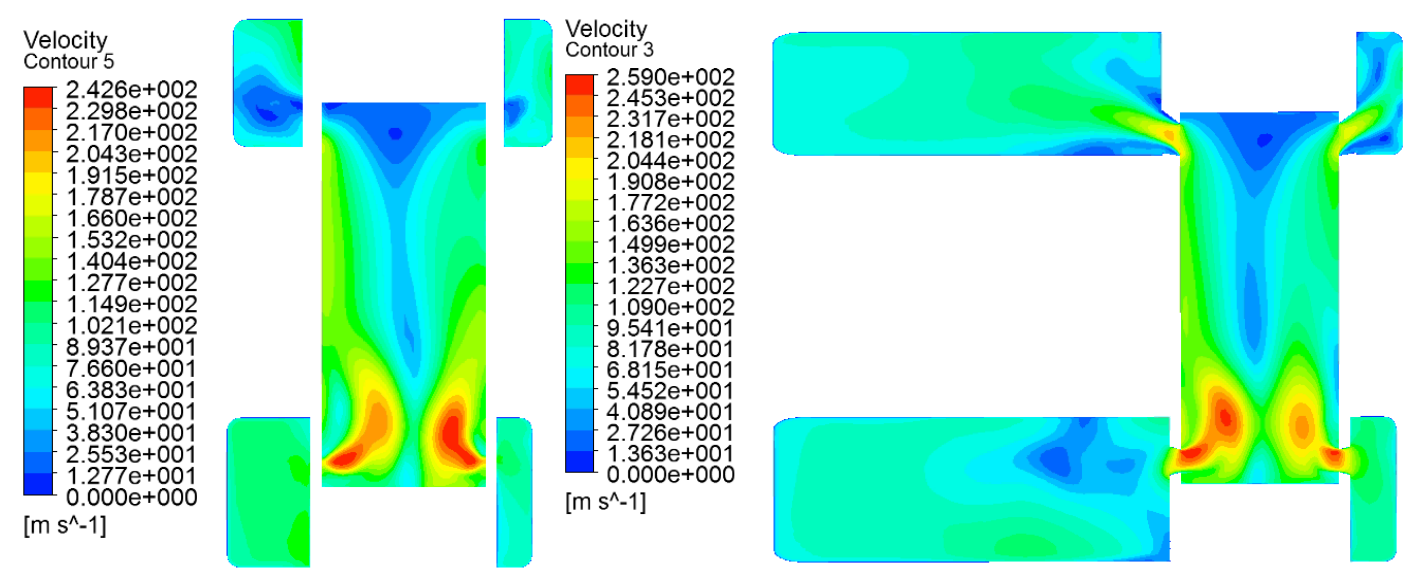

Fig. 14 Contour of the velocity in the longitudinal plane yz (on the left) and in the longitudinal plane rotated relative to the plane $y z$ (on the right) for cylinder no. 3 of the considered geometric model

\section{Conclusions}

In the considered geometry, too high value of the swirl coefficient was obtained and it was noticed that the factor escaping from the outlet duct is reflected from the internal walls of the outlet collector. The high value of the "swirl" coefficient was manifested by very high tangential speeds of the medium away from the cylinder axis. Unfortunately, part of the volume near the axis was not properly mixed. It has relatively low speeds, which is unfavorable from the point of view of flushing the cylinder. The high value of the "swirl" coefficient also indicates that a greater amount of energy is transferred to the losses associated with the formation of vortices. In the next step, it was decided to reduce the value of the "swirl" coefficient, and thus to increase the mass flow rate.

\section{Acknowledgements}

Acknowledgement: This work has been realised in the cooperation with the Construction Office of WSK "PZL-KALISZ" S.A." and is part of Grant Agreement No. POIR.01.02.00-00-0002/15 financed by the Polish National Centre for Research and Development.

\section{References}

1. Z. Czyż, K. Siadkowska, and R. Sochaczewski, "CFD Analysis of Charge Exchange in an Aircraft Opposed-Piston Diesel Engine", MATEC Web of Conferences, vol. 252, 04002, 2019, https://doi.org/10.1051/matecconf/201925204002.

2. K. Siadkowska, and Z. Czyż, "Selecting a material for an aircraft diesel engine block", Combustion Engines = Silniki Spalinowe, vol. 178, no. 3, pp. 4-8, 2019.

3. L. Grabowski, Z. Czyż, and K. Kruszczynski, "Numerical Analysis of Cooling Effects of a Cylinders in Aircraft SI Engine", SAE Technical Paper, 2014-01-2883, 2014, doi:10.4271/2014-01-2883. 
4. M. Bialy, M. Wendeker, P. Magryta, Z. Czyż, and R. Sochaczewski, "CFD Model of the Mixture Formation Process of the CNG Direct Injection Engine", SAE Technical Paper, 2014-01-2575, 2014, doi:10.4271/2014-01-2575.

5. C. Abagnale, M. C. Cameretti, L. De Simio, M. Gambino, S. lannaccone, and R. Tuccillo, "Combined numerical-experimental study of dual fuel diesel engine", Energy Procedia, vol. 45, pp. 721-730. doi: 10.1016/j.egypro.2014.01.077.

6. R. Sochaczewski, Z. Czyż, K. Siadkowska, "Modeling a fuel injector for a two-stroke diesel engine", COMBUSTION ENGINES / SILNIKI SPALINOWE, no 3, vol. 170, s. 147-153, 2017.

7. J. Czarnigowski, M. Wendeker, P. Jakliński, K. Pietrykowski, A. Nazarewicz, M. Gęca, and T. Zyska, "Testing non-uniformity of the combustion process in a radial aircraft engine", SAE Technical Paper, 2007-01-2074.

8. M. Gęca, M. Wendeker, and G. Litak, "Combustion variability and uniqueness in cylinders of a large power radial engine", Journal of Vibroengineering, vol. 14, p. 582-590, 2012.

9. N. B. Hung, S. Jaewon, and O. Lim, "A Study of the Scavenging Process in a Two-stroke Free Piston Linear Engine using CFD," Energy Procedia, vol. 142, pp. 1353-1360, 2017.

10. N. B. Hung, and O. Lim, "A review of free piston linear engines", Applied Energy, 178, pp. 78-97, 2016. 